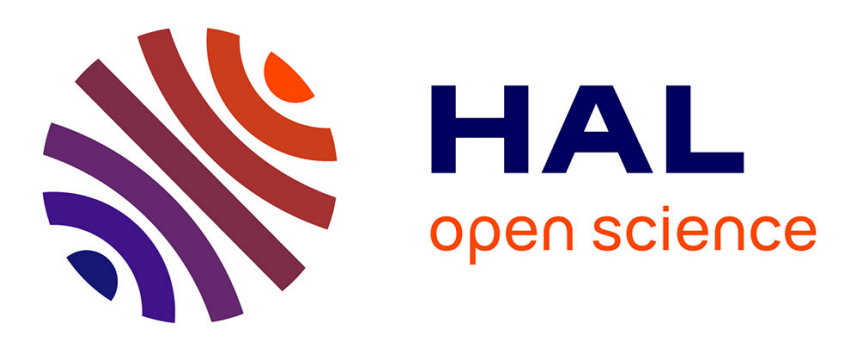

\title{
Why do music-based interventions benefit persons with neurodegenerative disease?
}

\author{
Lise Hobeika, Séverine Samson
}

\section{To cite this version:}

Lise Hobeika, Séverine Samson. Why do music-based interventions benefit persons with neurodegenerative disease?. Music and the Aging Brain, 2020, pp.333 - 349. 10.1016/b978-0-12-817422-7.00013-4 . hal-03127010

\section{HAL Id: hal-03127010 \\ https://hal.science/hal-03127010}

Submitted on 1 Feb 2021

HAL is a multi-disciplinary open access archive for the deposit and dissemination of scientific research documents, whether they are published or not. The documents may come from teaching and research institutions in France or abroad, or from public or private research centers.
L'archive ouverte pluridisciplinaire HAL, est destinée au dépôt et à la diffusion de documents scientifiques de niveau recherche, publiés ou non, émanant des établissements d'enseignement et de recherche français ou étrangers, des laboratoires publics ou privés. 


\title{
Why do music-based interventions benefit persons with neurodegenerative disease?
}

\author{
Lise Hobeika ${ }^{1,2}$ and Séverine Samson ${ }^{1,3}$
}

\author{
${ }^{1}$ Equipe Neuropsychologie: Audition, Cognition, Action, Laboratoire PSITEC EA 4072, UFR de Psychologie, \\ Université de Lille, Pont de Bois, Lille, France \\ ${ }^{2}$ CNRS, Ircam, Sorbonne Université, Ministère de la Culture, Sciences et Technologies de la Musique et du \\ son, STMS, F-75004 Paris, France \\ ${ }^{3}$ AP-HP, GH Pitié-Salpêtrière- Charles Foix, Paris, France \\ This is a draft. The published version is available at : https://doi.org/10.1016/B978-0-12-817422-7.00013-4
}

\begin{abstract}
Alzheimer disease (AD) is a neurodegenerative disease impacting cognitive, emotional, and social functioning. Given the limited effectiveness of the pharmacological approach in overcoming these difficulties, the development of non-drug treatment and particularly music-based interventions appear to be an efficient tool to overcome those difficulties. However, the factors that explain their efficacy are not clarified yet. Music is a fundamental human activity that can have a strong emotional and cognitive impact. Moreover, musical interventions promote social interactions during which participants coordinate their movements to a common rhythm. In this chapter, we will discuss the idea that interpersonal coordination supported by music can improve social functioning and non-verbal communication in patients with $\mathrm{AD}$. We will also propose methods to study the benefits of music interventions on aged persons in clinical context and in particular in patients with AD.
\end{abstract}

Keywords: Alzheimer disease, music intervention, non-verbal communication, interpersonal coordination, rhythmic entrainment, social engagement

\section{Introduction}

For a long time, musical practices with a therapeutic vocation have existed and its use in this context has considerably amplified during the last decades (Sihvonen et al., 2017; van der Steen et al., 2018). Widely relayed by the media, music-based interventions have shown growing success in persons with neurodegenerative disease and their caregivers. An important field of application of these methods concerns the management of the different stages of cortical neurodegenerative pathologies such as Alzheimer's disease (AD). Considering the limited impact of pharmacological treatments with the iatrogenic effects of medication in these patients, several health institutions recommended in parallel the development of non-pharmacological approaches to alleviate some symptoms (National Institute for
Health and Care Excellence, 2018).

$\mathrm{AD}$ is a neurodegenerative disorder that is associated with several cognitive and emotional deficits. Symptoms usually include memory (Hodges, 2000), and mood dysfunction (Christensen, Griffiths, Mackinnon, \& Jacomb, 1997) and, in particular, depression and anxiety (Chu et al., 2014). These deficits have been associated with behavioral disorders such as agitation, and sometimes aggressiveness, which are the main causes of patients' institutionalization (Luppa, Luck, Brähler, König, \& Riedel-Heller, 2008; Toot, Swinson, Devine, Challis, \& Orrell, 2017) and are also at the root of caregivers' suffering (Black \& Almeida, 2004). All together, these difficulties lead to a progressive social deterioration, including a loss of sense of self and identity (Caddell \& Clare, 2010), 
and weakening of interpersonal relationships that may stem from a decline in emotional comprehension (Shimokawa et al., 2001), and communication difficulties (Feyereisen \& Hupet, 2007; Potkins et al., 2003). Such social dysfunctions might be aggravated by patients' decline of verbal function, and may impact as well organization of units and staff. The most common language deficits are lexical access, as well as speech disfluencies such as aposiopesis (sentences left unfinished), logorrhea (excessive wordiness with incoherent talkativeness), palilalia (repetition of syllables, words or phrases; Hier, Hagenlocker, \& Shindler, 1985), abnormal turn-taking (Perkins, Whitworth, \& Lesser, 1998; Ripich, Vertes, Whitehouse, Fulton, \& Ekelman, 1991), and empty discourse (Nicholas, Obler, Albert, \& Helm-Estabrooks, 1985). In more severely detoriated patients, language can be totally absent (Caramelli, Mansur, \& Nitrini, 1998). Thus, AD patients' attempts to share their thoughts or engage in dialogue for social purposes may go unnoticed because of their verbal communication deficits (Potkins et al., 2003; Small, Geldart, Gutman, Ann, $\&$ Scott, 1998). The combination of memory, mood and communication disorders increases social isolation reducing therefore the quality of life of patients with neurodegenerative diseases (Klimova, Maresova, Valis, Hort, \& Kuca, 2015). However, while verbal communication is impaired, non-verbal communication appears to be relatively spared at least in these cases reports (Tzortzis, Goldblum, Dang, Forette, \& Boller, 2000; Warren, Warren, Fox, $\&$ Warrington, 2003). It has therefore been proposed that non-verbal skills might compensate verbal difficulties in these patients (Schiaratura, Di Pastena, Askevis-Leherpeux, \& Clément, 2015).

Musical interventions are thought to improve mood regulation, social functioning and cognition of patients with $\mathrm{AD}$, as well as the well-being of their caregivers. However, the factors that explain their therapeutic efficacy are not yet clarified. In our chapter, we want to shed light on the intervention elements that appear to benefit patients with different stages of the $\mathrm{AD}$, and will discuss the idea that synchronization to music, which is relatively spared even in advanced stages of the disease, can enhance inter-personal coordination, and thus can improve social functioning and sustain non-verbal communication skills. For this purpose, we will also review the evidence from psychology, neuroscience and embodied music cognition that may have important implications to understand and to improve the efficacy of music-based interventions in patients with AD.

\section{Music-based interventions in patients with Alzheimer's disease}

Several reasons justify the use of music as a privileged support for therapy. Appreciated by patients of all ages, backgrounds and socio-cultural levels, music is widely accessible, easy to utilize, enjoyed by the majority of people and thus a potentially playful and motivating tool for rehabilitation. Indeed, music naturally conveys strong emotions (Koelsch, 2014) and induces extremely pleasurable experiences such as chill (Blood \& Zatorre, 2001; Pankseep, 1995). It seems that patients with Alzheimer's disease retain an intriguing sensitivity to music, even at advanced stages (Baird \& Samson, 2015; Cuddy \& Duffin, 2005; Johnson et al., 2011). Music can trigger souvenirs, such as autobiographical memory ( Baird \& Samson, 2014; Cuddy, Sikka, Silveira, Bai, \& Vanstone, 2017; El Haj, Postal, \& Allain, 2012). As demonstrated by neuroimaging and pharmacological studies in healthy participants, music can modulate emotional state and motivation (Ferreri et al., 2019; Mas-Herrero, Dagher, \& Zatorre, 2018; Salimpoor et al., 2013; Salimpoor, Zald, Zatorre, Dagher, \& McIntosh, 2015). Its unique ability to elicit both emotions and memories means that it can potentially provide a link to the person's past. Furthermore, music can be a social activity. It is commonly used for communication (Mehr, Singh, York, Glowacki, \& Krasnow, 2018) thus may promote feelings of interconnectedness among patients and between patients their caregivers. Overall, music appears as an ideal media to present to persons with potential memory and mood disorders and diminished social interactions.

Music-based interventions involve a large variety of activities that can be divided in two types: passive (or receptive) or active (or participatory) interventions. In receptive interventions, patients listen to music or songs performed by musicians, caregivers or from audio or video recordings. In participatory interventions, patients are encouraged to join the music-making by singing, playing simple instruments, dancing or simply moving with the beats. Those musical activities can be performed individually or more frequently in groups with the presence of another person (caregiver or therapist) or other persons (i.e. patients' group). Since it remains difficult to induce passive listening without any active processes, passive and active sessions are generally combined during music-based interventions. However, the few studies examining active and passive music-based interventions as 
compared to a control group with usual care suggest that participatory activities bring greater benefits than passive listening to music (Sakamoto, Ando, \& Tsutou, 2013; Särkämö et al., 2014). In a study in which short- and long-term effects of such interventions were assessed, Sakamoto and colleagues (2013) showed that the active interventions requiring patients to sing and to dance on music led to the greatest improvement in emotional state and better long-term reduction of behavioral problems. In another study, Särkämo and colleagues also demonstrated that both types of music interventions improved mood and remote episodic memory. However, only the active interventions enhanced short-term and working memory, and caregiver well-being (Särkämö et al., 2014). Taken together, these findings support the idea that involving patients with $\mathrm{AD}$ at the motor level in the musical interventions may provide most important benefits.

An potential explanation of the advantage of active intervention is first the emotional content. We know that moving to the rhythm of music provides pleasure (Janata, Tomic, \& Haberman, 2012). The audiomotor coupling and the temporal expectations produced by the perception of the musical beat would stimulate the reward brain network, inducing therefore pleasure (Salimpoor, Benovoy, Larcher, Dagher, \& Zatorre, 2011). Moreover, an important component of those interventions is the social aspect. Some studies suggest that the social context modify music perception. Thus, the presence of a singer which is often the case in active interventions - can improve the engagement of patients in the musical task compared to a music recording (Holmes, Knights, Dean, Hodkinson, \& Hopkins, 2006; Lesaffre, Moens, \& Desmet, 2017; Sherratt, Thornton, \& Hatton, 2004). Moreover, sharing a musical rhythm with others may be a way to connect with them and share positive emotions (Tarr, Launay, $\&$ Dunbar, 2014). Therefore, we propose that the therapeutic benefits of music lie in its hedonic and emotional component coupled with its role in communication and in the creation of social bonds (social bonding), which patients are often lacking. However, the mechanisms underlying the beneficial impacts of music in these patients and the extent to which the efficacy of music seems to surpass that of other pleasant activities need to be further explored.

\section{Interpersonal coordination in music to improve social functioning}

\section{Motor behaviors and social bonding}

When verbal communication is impaired, patients with $\mathrm{AD}$ may rely on non-verbal communication to connect with others (Schiaratura et al., 2015). Non-verbal communication describes conscious or unconscious behaviors that share information about our mental state to others without the use of language. Non-verbal communication can take various forms such as facial expressions, body posture, interpersonal distances or eye gaze contact. All these behaviors can be used to communicate to others information about our intentions, our emotional state or our willingness to bond with them.

Other non-verbal communication behaviors rely on the coordination of movements with others in time and space, i.e. interpersonal coordination. Interpersonal coordination is at the core of social life, as it is necessary for most social interactions to succeed: such as doing collective sports, moving a piece of furniture with a friend or even having a conversation. In the musical domain, interpersonal coordination such as singing, dancing or music playing in group are activities that allow communicating to others the willingness to bond. Anthropologists suggest that those musical activities, found in churches, in armies or in sport teams, create a feeling of cohesion between individuals by weakening the boundaries between the self and the group (Ehrenreich, 2007; Radcliffe-Brown, 1952). It has also been shown that individuals singing in unison, or moving together on musical beats have a higher tendency to cooperate with each others (Hove \& Risen, 2009; Mogan, Fischer, \& Bulbulia, 2017). This effect is not specific to musical interaction. Moving together by simply walking in step, rocking chairs synchronously or tapping to a metronome beat with others can promote social cohesion (Demos, Chaffin, Begosh, Daniels, \& Marsh, 2012; Reddish, Fischer, \& Bulbulia, 2013; Wiltermuth \& Heath, 2009). Thus, singing or music making can be a form of non-verbal communication between individuals, promoting cohesion and cooperation between individuals.

At the physiological level, the social effect of interpersonal coordination seems to be associated with the release of oxytocin. As reported by several authors, this neurohormone is known for its role in social behaviors, as it induces increase in trust (Kosfeld, Heinrichs, Zak, Fischbacher, \& Fehr, 2005), cooperation (Zhang, Gross, De Dreu, \& Ma, 2018) and empathy (Domes, Heinrichs, Michel, Berger, \& Herpertz, 2007). Synchronized behaviors could also 
stimulate the endogenous opioid system and particularly endorphins, which are neurohormones associated with pleasure and well-being, and have a role in social bonding in human and non-human primate (Cohen, Ejsmond-frey, Knight, \& Dunbar, 2010; Martel, Nevison, Simpson, \& Keverne, 1995; Schino \& Troisi, 1992; Tarr et al., 2014). We can therefore suggest that physiological responses resulting from interpersonal coordination activities could, at least in part, mediate the impact of musical interventions on social interactions.

In active musical interventions, patients with AD spontaneously sing or move with the musical rhythm with others (i.e. therapist, other patients or caregivers). We hypothesize that the success of those interventions may in part rely on their benefits on social behaviors. Moving on music with others could induce patients with $\mathrm{AD}$ to interact positively with others, to feel included in a group, and thus to improve social functioning. It could also increase trust and collaboration with the surroundings and with the caregivers. This interpretation, based on hypotheses raised by the study of healthy young adults, deserves to be tested in aged populations. Although it seems in coherence with the fact that participatory musical interventions have greater efficacy than receptive ones on patients with $A D$ well-being (see section 1), further research is still needed to better understand the social cognitive functioning of these patients, and their communication behaviors.

\section{Social cognition abilities}

The few studies investigating social cognitive abilities in patients with $\mathrm{AD}$ found a decreased in theory of mind (Fernandez-Duque, Baird, \& Black, 2009; Gregory et al., 2002), emotion recognition (Albert, Cohen, \& Koff, 1991; Bediou et al., 2009) and empathy (Fernandez-Duque, Hodges, Baird, \& Black, 2010). These high-order social cognitive functions allow the understanding of others and support non-verbal communication. By using active music interventions in pathological as well as in physiological aging, we can expect to stimulate social cognitive abilities and to maintain these skills as long as possible. Since no study has addressed the relationship between interpersonal coordination and social cognitive abilities in $\mathrm{AD}$, we will report evidence obtained in individuals with typical and atypical development. We are aware that the explanatory factors are very different in neurodevelopmental and degenerative pathology. However, even if the pathological contexts are different, we may treat similar social symptoms with the same procedure. These results may be used as a basis for finding methods to stimulate social capacities in $\mathrm{AD}$, whose implementation will require adaptation.

According to a large literature, the development of social cognition skills is partially linked to interpersonal coordination, synchronization and imitation (Asendorpf \& Baudonnière, 1993; Feldman, 2007b, 2007a; Harrist \& Waugh, 2002). In a longitudinal study testing the development of empathy on children, Feldman (2007a) found an association between mother-infant synchrony at 3 months and empathy capacities of adolescents at 13 years (Feldman, 2007a). Engaging in interpersonal coordination may be a way to restore social cognition skills. Some evidence to support this idea is provided in a recent study on individuals with autism spectrum disorder. In this study a training program based on dance and movements (focusing on interpersonal synchronization and imitation) improved their social abilities (Koehne, Behrends, Fairhurst, \& Dziobek, 2016). The link between interpersonal synchronization and social cognition abilities reported in these studies is usually explained by the fact that the understanding of others' actions may be based on motor resonance, i.e. the mapping of others' action in our own motor repertoire (Panasiti, Porciello, \& Aglioti, 2017). The so-called mirror system is activated during both the observation and the realization of the same action (Aglioti, Cesari, Romani, \& Urgesi, 2008; Calvo-Merino, Glaser, Grèzes, Passingham, \& Haggard, 2005). Engaging individuals in interpersonal synchronization may be an appropriate way to stimulate this association between observation and motor resonance, boosting therefore the ability to understand others' action.

Interestingly, music interventions appear as perfect situations to engage in interpersonal synchronization. In participatory musical interventions, individuals can easily synchronize their movements thanks to the presence of musical rhythm. It would also be interesting to test if the success of those interventions can be linked to an improvement in social cognitive functioning of patients with $\mathrm{AD}$, and particularly to an amelioration of empathy, emotions recognition and theory of mind. However, to provide support to these findings or interpretations, appropriate evaluating tools and methods to measure synchronization to music and to others should be designed. 


\section{Methodological aspects related to the impact of musical intervention in patients with AD}

A large number of studies claim positive effects of music-based interventions on emotions, well-being, social functioning, and even sometimes on cognition in patients with $\mathrm{AD}$, as well as on caregivers well-being (Choi, Lee, Cheong, \& Lee, 2009; Raglio et al., 2012; Svansdottir \& Snaedal, 2006; Ueda, Suzukamo, Sato, \& Izumi, 2013). Yet, those conclusions need to be interpreted with caution. The results of a recent meta-analysis questions the validity of such positive effects (van der Steen et al., 2018). Indeed, many studies still have methodological biases that weakened the conclusions: small sample sizes, lack of blind assessors, lack of randomization, the absence of a control group with no intervention (i.e. with treatment as usual) and of a group with a control (non-musical) intervention. This latter group is necessary to control for social stimulation and hedonic factors, to determine whether or not any pleasant social activity could have similar effects. Moreover, the potency of the treatment vary considerably between individuals. More studies need to be conducted to document the efficacy of music on patients with $\mathrm{AD}$.

As already mentioned, the proposed musical activities in those prior studies cover a large variety of skills from music listening individually to music playing in groups. Therefore, it is not surprising that the reported studies lead to inconsistent results. Two main characteristics of those interventions can impact their potential effects: the social context (alone or in social presence) and as mentioned above, the type of intervention (passive or active intervention) (see Figure 1). These characteristics can change patients' engagement during the interventions, the pleasure felt but also the impact of such interventions on the social, emotional and cognitive functioning. To disentangle the influence of those factors and to understand the mechanisms underlying the positive impact of musical interventions, wellcontrolled studies using multimodal data, such as cognitive, emotional, social or psychophysiological recordings, are necessary.

Usually, the evaluation of musical interventions' impact includes the assessment of patients' mood and behavior as well as caregivers' quality of life. These evaluations are often performed using questionnaires filled by the patient (selfreported evaluation) or by a family or medical caregiver (hetero evaluation), depending on the disease progression. Frequently used questionnaires are the Behavior Pathology in Alzheimer's Disease Ratings Scale (BEHAVE-AD) that rates behavioral problems of dementia (Reisberg, Auer, \& Monteiro, 1997), the Cohen-Mansfield Inventory (CMAI) which rates agitated behaviors (Cohen-Mansfield, Marx, \& Rosenthal, 1989), the State-Trait Anxiety Inventory for Adults (STAI-A) that assesses mood and anxiety (Spielberger, Gorsuch, Lushene, Vagg, \& Jacobs, 1983) and the NeuroPsychiatric Inventory (NPI) which evaluates the severity and frequency of several behavioral functioning (e.g. delusions, hallucinations, agitation, disinhibition, sleep abnormalities) as well as caregivers distress (Sisco et al., 2000).

The questionnaires can be completed by objective measures such as the evaluation of physiological changes induced by musical intervention. Indeed, measures of cortisol level can be a marker of patients stress levels (Kirschbaum \& Hellhammer, 1994). Heart rate and blood pressure can also constitute an interesting marker of patients' affective state (de Witte, Spruit, van Hooren, Moonen, \& Stams, 2019; Sakamoto et al., 2013). However, we still need additional studies to confirm their relevance to examine the effect of music-based interventions on psychophysiological responses in patients with AD.

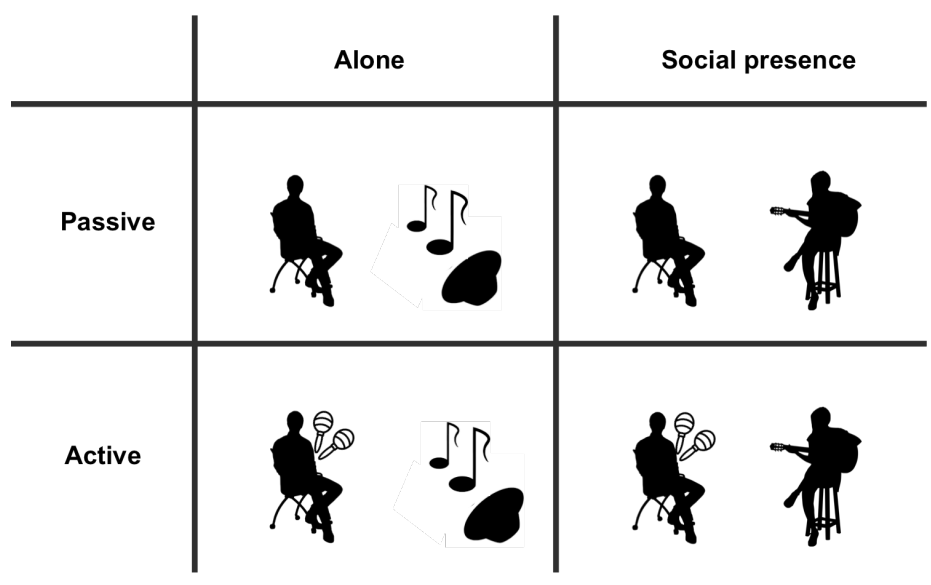

Figure 1 : Musical-based interventions can be classified according to the social context (alone or in social presence) and the motor engagement

(passive or active)

Quantitative measures of patients' engagement should also be considered to study the benefits of music-based interventions. Engagement in the musical activity can be analyzed at the motor, 
the emotional or the social level. Motor engagement is evaluated by the spontaneous motor reaction with music. Music is built on a strong regular rhythm that elicits spontaneous motor responses in listeners (Fraisse, 1982): people have the tendency to move in synchrony with musical beats (Leman \& Buhmann, 2017; Repp, 2005). The production of behaviors like singing, clapping, or the global quantity of body movements can provide measures of patients rhythmic entrainment with the music (Ghilain et al., in prep.; Holmes et al., 2006; Lesaffre et al., 2017; Sherratt et al., 2004). The emotional engagement can be evaluated using methods from social psychology (Schiaratura, 2008). The production of non-verbal behaviors in patients with dementia have already been successfully measured in studies that have found benefits of music interventions (Narme et al., 2014). The measurements of the production of emotional facial or vocal expressions, or of body postures and gestures seem to be very promising markers of patients' emotional state. They can be decoded from video recordings of the participants, providing information related to the quality of nonverbal behaviors produced in response to music listening or practicing.

Music-based interventions in groups can be analyzed as a joint action supported by the presence of music. The degree of synchronization between participants' behaviors reflects social engagement. As already mentioned, individuals tend to synchronize their behaviors with others', and especially rhythmic movements when they are in a group. This spontaneous interpersonal synchronization, called motor entrainment or alignment, has been observed in laboratory studies, in which dyads of participants unconsciously or voluntarily synchronized their finger tapping (Oullier, Guzman, Jantzen, Lagarde, \& Kelso, 2008), their steps while walking side by side (van Ulzen, Lamoth, Daffertshofer, Semin, \& Beek, 2008) or the rhythm of rocked chairs sways (Richardson, Marsh, Isenhower, Goodman, \& Schmidt, 2007). We can therefore propose that interpersonal synchronization of rhythmic movements might provide relevant indexes to measure patients' engagement with others in a musical context (Ghilain, Schiaratura, Singh, Lesaffre, \& Samson, 2019). In addition, the synchronization of individuals' posture, gestures, facial expression and eye gaze, which have long been regarded as the regulators of social interaction, are notably important for the development of rapport and personal relationships (Lakin, Jefferis, Cheng, \& Chartrand, 2003). Rigorous measures to quantify the production of rhythmic joint actions in musical activities should be developed to examine their relationships with social cognitive abilities.

Finally, patients' rhythmic abilities can also be measured by asking participants to tap along with the musical beat. Sensorimotor precision in tapping tasks gives a measure of individuals' prediction and adaptative abilities (Keller, Novembre, \& Hove, 2014). The variability of the tapping can be provided by assessing the sensorimotor consistency (Dalla Bella et al., 2016). Usually, such rhythmic behaviors are measured in tasks involving finger or hand tapping with music or metronome beats. Very few studies examined this type of rhythmic abilities in patients with $\mathrm{AD}$ or mild cognitive impairment (Kluger, Gianutsos, Golomb, Ferris, \& Reisberg, 1997; Suzumura et al., 2016). Even if gross motor skills appear clinically normal at the early stage of $\mathrm{AD}$, motor control deficits may be associated with disease progression (Bangert \& Balota, 2012; Kluger et al., 1997; Suzumura et al., 2016). Yet, they often pass undetected in comparison to cognitive impairments and to decline in daily living activities (de Paula et al., 2016; Yan, Rountree, Massman, Doody, \& Li, 2008). A careful examination of the accuracy and the variability of sensorimotor synchronization with musical rhythms might offer additional and relevant behavioral markers of interpersonal coordination and deserve to be examined in patients with $\mathrm{AD}$ disease.

\section{Conclusion}

Music is a universal human activity that can play a key role in communication, social interaction, and mood regulation. The richness of music on the emotional, motor and social stimulations might explain the success of music-based interventions as a non-pharmacological treatment for patients with $\mathrm{AD}$. Among the different musical activities responsible to their effectiveness, the synchronization of movements to the musical rhythm, which is relatively spared even in advanced stages of $\mathrm{AD}$, is largely used. It seems to induce a lot of pleasure, improve emotion regulation, stimulate motor control as well as social functioning. However, more specific and control studies with appropriate and innovative tools need to be developed to assess and to train elderly persons. Such technical and scientific progresses that combine methods from psychology, neuroscience and embodied music cognition will allow a better understanding of the factors that contribute to the positive effect of music-based interventions in patients with AD. This knowledge will help to design rhythmic training programs. By 
adapting the musical activities to the patients' needs, personalized training sessions will be proposed to reduce social isolation and to improve the quality of life of elderly people and of their family and medical caregivers.

\section{Acknowledgements}

Grant support was provided by the Institut Universitaire de France and the French Foundation France Alzheimer to Séverine Samson.

\section{References}

Aglioti, S. M., Cesari, P., Romani, M., \& Urgesi, C. (2008). Action anticipation and motor resonance in elite basketball players. Nature Neuroscience, 11(9), 1109-1116. https://doi.org/10.1038/nn.2182

Albert, M. S., Cohen, C., \& Koff, E. (1991). Perception of Affect in Patients With Dementia of the Alzheimer Type. Archives of Neurology, 48(8), 791-795. https://doi.org/10.1001/archneur.1991.00530200027013

Asendorpf, J. B., \& Baudonnière, P. M. (1993). Self-Awareness and Other-Awareness: Mirror Self-Recognition and Synchronic Imitation Among Unfamiliar Peers. Developmental Psychology, 29(1), 88-95. https://doi.org/10.1037/0012-1649.29.1.88

Baird, Amee, \& Samson, S. (2014). Music evoked autobiographical memory after severe acquired brain injury: Preliminary findings from a case series. Neuropsychological Rehabilitation, 24(1), 125-143. https://doi.org/10.1080/09602011.2013.858642

Baird, Amee, \& Samson, S. (2015). Music and dementia. In Progress in Brain Research (Vol. 217, pp. 207-235). https://doi.org/10.1016/bs.pbr.2014.11.028

Bangert, A. S., \& Balota, D. A. (2012). Keep up the pace: Declines in simple repetitive timing differentiate healthy aging from the earliest stages of Alzheimer's disease. Journal of the International Neuropsychological Society, 18(6), 1052-1063. https://doi.org/10.1017/S1355617712000860

Bediou, B., Ryff, I., Mercier, B., Milliery, M., Hanaff, M. A., D'Amato, T., ... Krolak-Salmon, P. (2009). Impaired social cognition in mild alzheimer disease. Journal of Geriatric Psychiatry and Neurology, 22(2), 130-140. https://doi.org/10.1177/0891988709332939

Black, W., \& Almeida, O. P. (2004). A systematic review of the association between the Behavioral and Psychological Symptoms of Dementia and burden of care. International Psychogeriatrics, 16(3), 295-315. https://doi.org/10.1017/s1041610204000468

Blood, A. J., \& Zatorre, R. J. (2001). Intensely pleasurable responses to music correlate with activity in brain regions implicated in reward and emotion. Proceedings of the National Academy of Sciences, 98(20). https://doi.org/10.1073/pnas.191355898

Caddell, L. S., \& Clare, L. (2010). The impact of dementia on self and identity: A systematic review. Clinical Psychology Review, 30(1), 113-126. https://doi.org/10.1016/j.cpr.2009.10.003

Calvo-Merino, B., Glaser, D. E., Grèzes, J., Passingham, R. E., \& Haggard, P. (2005). Action observation and acquired motor skills: an FMRI study with expert dancers. Cerebral Cortex (New York, N.Y. : 1991), 15(8), 1243-1249. https://doi.org/10.1093/cercor/bhi007

Caramelli, P., Mansur, L. L., \& Nitrini, R. (1998). Language and Communication Disorders in Dementia of the Alzheimer Type. In Handbook Of Neurolinguistics (Adacemic P, pp. 463-473). Woodhead Publishing Limited. https://doi.org/10.1016/B978-012666055-5/50036-8

Choi, A. N., Lee, M. S., Cheong, K. J., \& Lee, J. S. (2009). Effects of group music intervention on behavioral and psychological symptoms in patients with dementia: A pilot-controlled trial. International Journal of Neuroscience, 119(4), 471-481. https://doi.org/10.1080/00207450802328136

Christensen, H., Griffiths, K., Mackinnon, A., \& Jacomb, P. (1997). A quantitative review of cognitive deficits in depression and Alzheimer-type dementia. Journal of the International Neuropsychological Society: JINS, 3(6), 631-651. Retrieved from http://www.ncbi.nlm.nih.gov/pubmed/9448376

Chu, H., Yang, C. Y., Lin, Y., Ou, K. L., Lee, T. Y., O’Brien, A. P., \& Chou, K. R. (2014). The Impact of Group Music Therapy on Depression and Cognition in Elderly Persons With Dementia: A Randomized Controlled Study. Biological Research for Nursing, 16(2), 209-217. https://doi.org/10.1177/1099800413485410

Cohen-Mansfield, J., Marx, M. S., \& Rosenthal, A. S. (1989). A description of agitation in a nursing home. Journals of Gerontology, 44(3). https://doi.org/10.1093/geronj/44.3.M77

Cohen, E., Ejsmond-frey, R., Knight, N., \& Dunbar, R. I. M. (2010). Rowers' high: behavioural synchrony is correlated with elevated pain thresholds. Biology Letters, 6(1), 106108. https://doi.org/10.1098/rsbl.2009.0670

Cuddy, L. L., \& Duffin, J. (2005). Music, memory, and Alzheimer's disease: Is music recognition spared in dementia, and how can it be assessed? Medical Hypotheses, 64(2), 229-235. https://doi.org/10.1016/j.mehy.2004.09.005

Cuddy, L. L., Sikka, R., Silveira, K., Bai, S., \& Vanstone, A. (2017). Music-evoked autobiographical memories (MEAMs) in alzheimer disease: Evidence for a positivity effect. Cogent Psychology, 4(1), 1-20. https://doi.org/10.1080/23311908.2016.1277578

Dalla Bella, S., Farrugia, N., Benoit, C., Begel, V., Verga, L., Harding, E., \& Kotz, S. A. (2016). BAASTA : Battery for the Assessment of Auditory Sensorimotor and Timing Abilities. Behavior Research Methods, 49(3), 1128-1145. https://doi.org/10.3758/s13428-016-0773-6

de Paula, J. J., Albuquerque, M. R., Lage, G. M., Bicalho, M. A., Romano-Silva, M. A., \& Malloy-Diniz, L. F. (2016). Impairment of fine motor dexterity in mild cognitive impairment and Alzheimer's disease dementia: Association with activities of daily living. Revista Brasileira de Psiquiatria, 38(3), 235-238. https://doi.org/10.1590/1516-4446-2015-1874

de Witte, M., Spruit, A., van Hooren, S., Moonen, X., \& Stams, G.-J. (2019). Effects of Music Interventions on StressRelated Outcomes: A Systematic Review and Two MetaAnalyses. Health Psychology Review, O(0), 1-62. https://doi.org/10.1080/17437199.2019.1627897

Demos, A. P., Chaffin, R., Begosh, K. T., Daniels, J. R., \& Marsh, K. L. (2012). Rocking to the beat: effects of music and partner's movements on spontaneous interpersonal 
coordination. Journal of Experimental Psychology. General, 141(1), 49-53. https://doi.org/10.1037/a0023843

Domes, G., Heinrichs, M., Michel, A., Berger, C., \& Herpertz, S. C. (2007). Oxytocin Improves "Mind-Reading" in Humans. Biological Psychiatry, 61(6), 731-733. https://doi.org/10.1016/j.biopsych.2006.07.015

Ehrenreich, B. (2007). Dancing in the streets: A history of collective joy. New York: Metropolitan Books.

El Haj, M., Postal, V., \& Allain, P. (2012). Music Enhances Autobiographical Memory in Mild Alzheimer's Disease. Educational Gerontology, 38(1), 30-41. https://doi.org/10.1080/03601277.2010.515897

Feldman, R. (2007a). Mother-Infant Synchrony and the Development of Moral Orientation in Childhood and Adolescence: Direct and Indirect Mechanisms of Developmental Continuity. American Journal of Orthopsychiatry, 77(4), 582-597.

Feldman, R. (2007b). Parent-infant synchrony and the construction of shared timing; physiological precursors, developmental outcomes, and risk conditions. Journal of Child Psychology and Psychiatry and Allied Disciplines, 48, 329-354. https://doi.org/10.1111/j.14697610.2006.01701.x

Fernandez-Duque, D., Baird, J. A., \& Black, S. E. (2009). Falsebelief understanding in frontotemporal dementia and Alzheimer's disease. Journal of Clinical and Experimental Neuropsychology, 31(4), 489-497. https://doi.org/10.1080/13803390802282688

Fernandez-Duque, D., Hodges, S. D., Baird, J. A., \& Black, S. E. (2010). Empathy in frontotemporal dementia and Alzheimer's disease. Journal of Clinical and Experimental Neuropsychology, 32(3), 289-298.

Ferreri, L., Mas-Herrero, E., Zatorre, R. J., Ripollés, P., GomezAndres, A., Alicart, H., ... Rodriguez-Fornells, A. (2019). Dopamine modulates the reward experiences elicited by music. Proceedings of the National Academy of Sciences, 116(9), 3793-3798. https://doi.org/10.1073/pnas.1811878116

Feyereisen, P., \& Hupet, M. (2007). Pragmatic skills in the early stages of Alzheimer' s disease : an analysis by means of a referential communication task. International Journal of Language, 42(1), 1-17. https://doi.org/10.1080/13682820600624216

Fraisse, P. (1982). Rhythm and Tempo. In Psychology of Music (pp. 149-180).

Ghilain, M., Schiaratura, L., Lesaffre, M., Six, J., Clément, S., \& Samson, S. (n.d.). Does a life performance impacts rhythmic synchronization to music and metronome in Alzheimer disease? In Prep.

Ghilain, M., Schiaratura, L., Singh, A., Lesaffre, M., \& Samson, S. (2019). Is music special for people with dementia. In A Baird, S. Garrido, \& J. Tamplin (Eds.), Music and dementia: from cognition to therapy (Oxford Uni).

Gregory, C., Lough, S., Stone, V., Erzinclioglu, S., Martin, L., Baron-cohen, S., \& Hodges, J. R. (2002). Theory of mind in patients with frontal variant frontotemporal dementia and Alzheimer's disease: theoretical and practical implications. Brain, 125, 752-764.

Harrist, A. W., \& Waugh, R. M. (2002). Dyadic synchrony: Its structure and function in children's development. Developmental Review, 22, 555-592.

Hier, D. B., Hagenlocker, K., \& Shindler, A. G. (1985). Language disintegration in dementia: Effects of etiology and severity. Brain and Language, 25(1), 117-133. https://doi.org/10.1016/0093-934X(85)90124-5

Hodges, J. R. (2000). Memory in the dementias. In The Oxford handbook of memory (pp. 441-459).
Holmes, C., Knights, A., Dean, C., Hodkinson, S., \& Hopkins, V. (2006). Keep music live: music and the alleviation of apathy in dementia subjects. International Psychogeriatrics, 18(4), 623-630. https://doi.org/10.1017/s1041610206003887

Hove, M. J., \& Risen, J. L. (2009). It's All in the Timing: Interpersonal Synchrony Increases Affiliation. Social Cognition, 27(6), 949-960. https://doi.org/10.1521/soco.2009.27.6.949

Janata, P., Tomic, S. T., \& Haberman, J. M. (2012). Sensorimotor coupling in music and the psychology of the groove. Journal of Experimental Psychology: General, 141(1), 54-75. https://doi.org/10.1037/a0024208

Johnson, J. K., Chang, C.-C., Brambati, S. M., Migliaccio, R., Gorno-Tempini, M. L., Miller, B. L., \& Janata, P. (2011). Music recognition in frontotemporal lobar degeneration and Alzheimer disease. Cognitive and Behavioral Neurology: Official Journal of the Society for Behavioral and Cognitive Neurology, 24(2), 74-84.

Keller, P. E., Novembre, G., \& Hove, M. J. (2014). Rhythm in joint action : psychological and neurophysiological mechanisms for real-time interpersonal coordination. Philosophical Transactions of the Royal Society B: Biological Sciences, 369.

Kirschbaum, C., \& Hellhammer, D. H. (1994). Salivary cortisol in psychoneuroendocrine research: recent developments and applications. Psychoneuroendocrinology, 19(4), 313333.

Klimova, B., Maresova, P., Valis, M., Hort, J., \& Kuca, K. (2015). Alzheimer's disease and language impairments: social intervention and medical treatment. Clinical Interventions in Aging, 10, 1401

Kluger, A., Gianutsos, J. G., Golomb, J., Ferris, S. H., \& Reisberg, B. (1997). Motor/Psychomotor Dysfunction in Normal Aging, Mild Cognitive Decline, and Early Alzheimer's Disease: Diagnostic and Differential Diagnostic Features. International Psychogeriatrics, 9(S1), 307-316. https://doi.org/10.1017/s1041610297005048

Koehne, S., Behrends, A., Fairhurst, M. T., \& Dziobek, I. (2016). Fostering Social Cognition through an Imitation- and Synchronization-Based Dance/Movement Intervention in Adults with Autism Spectrum Disorder: A Controlled Proof-of-Concept Study. Psychotherapy and Psychosomatics, 85(1), 27-35. https://doi.org/10.1159/000441111

Koelsch, S. (2014). Brain correlates of music-evoked emotions. Nature Reviews Neuroscience, 15(3), 170 https://doi.org/10.1038/nrn3666

Kosfeld, M., Heinrichs, M., Zak, P. J., Fischbacher, U., \& Fehr, E. (2005). Oxytocin increases trust in humans. Nature, 435, 673-676. https://doi.org/10.1038/nature03701

Lakin, J. L., Jefferis, V. E., Cheng, C. M., \& Chartrand, T. L. (2003). The chameleon effect as social glue: evidence for the evolutionary significance of nonconscious mimicry. Journal of Nonverbal Behavior, 27(3), 145-162.

Leman, M., \& Buhmann, J. (2017). The empowering effects of being locked into the beat of the music. In Body, sound and space in music and beyond: multimodal explorations (SEMPRE S, pp. 13-28). Routledge.

Lesaffre, M., Moens, B., \& Desmet, F. (2017). Dementia treatment strategies. In The Routledge Companion to Embodied Music Interaction (pp. 294-303). Routledge.

Luppa, M., Luck, T., Brähler, E., König, H. H., \& Riedel-Heller, S. G. (2008). Prediction of institutionalisation in dementia: A systematic review. Dementia and Geriatric Cognitive Disorders, 26(1), 65-78. https://doi.org/10.1159/000144027 
Martel, F. L., Nevison, C. M., Simpson, M. J. A., \& Keverne, E. B. (1995). Effects of opioid receptor blockade on the social behavior of rhesus monkeys living in large family groups. Developmental Psychobiology, 28(2), 71-84. https://doi.org/10.1002/dev.420280202

Mas-Herrero, E., Dagher, A., \& Zatorre, R. J. (2018). Modulating musical reward sensitivity up and down with transcranial magnetic stimulation. Nature Human Behaviour, 2(1), 27-32. https://doi.org/10.1038/s41562017-0241-z

Mehr, S. A., Singh, M., York, H., Glowacki, L., \& Krasnow, M. M. (2018). Form and Function in Human Song. Current Biology, 28(3), 356-368.e5. https://doi.org/10.1016/j.cub.2017.12.042

Mogan, R., Fischer, R., \& Bulbulia, J. A. (2017). To be in synchrony or not? A meta-analysis of synchrony's effects on behavior, perception, cognition and affect. Journal of Experimental Social Psychology, 72(September), 13-20. https://doi.org/10.1016/j.jesp.2017.03.009

Narme, P., Clément, S., Ehrlé, N., Schiaratura, L., Vachez, S., Courtaigne, B., ... Samson, S. (2014). Efficacy of Musical Interventions in Dementia: Evidence from a Randomized Controlled Trial. Journal of Alzheimer's Disease, 38, 359369. https://doi.org/10.3233/JAD-130893

National Institute for Health and Care Excellence. (2018). Dementia: Assessment, management and support for people living with dementia and their carers. https://doi.org/10.1007/978-1-349-95810-8 867

Nicholas, M., Obler, L. K., Albert, M. L., \& Helm-Estabrooks, N. (1985). Empty speech in alzheimers disease and fluent aphasia. Journal of Speech and Hearing Research, 28, 405-410.

Oullier, O., Guzman, G. C. De, Jantzen, K. J., Lagarde, J., \& Kelso, J. A. S. (2008). Social coordination dynamics : Measuring human bonding. Social Neuroscience, 3(2), 178-192. https://doi.org/10.1080/17470910701563392

Panasiti, M. S., Porciello, G., \& Aglioti, S. M. (2017). The bright and the dark sides of motor simulation. Neuropsychologia, 105, 92-100. https://doi.org/10.1016/j.neuropsychologia.2017.05.020

Pankseep, J. (1995). The Emotional Sources of " Chills " Induced by Music. Music Perception: An Interdisciplinary Journal, 13(2), 171-207.

Perkins, L., Whitworth, A., \& Lesser, R. (1998). Conversing in dementia: A conversation analytic approach. Journal of Neurolinguistics, 11(1-2), 33-53. https://doi.org/10.1016/S0911-6044(98)00004-9

Potkins, D., Myint, P., Bannister, C., Tadros, G., Chithramohan, R., Swann, A., ... Margallo-Lana, M. (2003). Language impairment in dementia: Impact on symptoms and care needs in residential homes. International Journal of Geriatric Psychiatry, 18(11), 1002-1006. https://doi.org/10.1002/gps.1002

Radcliffe-Brown, A. R. (1952). Structure and function in primitive society. The free press Glencoe, Illinois.

Raglio, A., Bellelli, G., Mazzola, P., Bellandi, D., Giovagnoli, A. R., Farina, E., ... Trabucchi, M. (2012). Music, music therapy and dementia: A review of literature and the recommendations of the Italian Psychogeriatric Association. Maturitas, 72(4), 305-310. https://doi.org/10.1016/j.maturitas.2012.05.016

Reddish, P., Fischer, R., \& Bulbulia, J. (2013). Let' s Dance Together: Synchrony, Shared Intentionality and Cooperation, $8(8)$. https://doi.org/10.1371/journal.pone.0071182

Reisberg, B., Auer, S. R., \& Monteiro, I. M. (1997). Behavioral pathology in Alzheimer's disease (BEHAVE-AD) rating scale. International Psychogeriatrics, 8(3), 301-308.

Repp, B. H. (2005). Sensorimotor synchronization : A review of the tapping literature. Psychonomic Bulletin \& Review, 12(6), 969-992.

Richardson, M. J., Marsh, K. L., Isenhower, R. W., Goodman, J. R. L., \& Schmidt, R. C. (2007). Rocking together : Dynamics of intentional and unintentional interpersonal coordination. Human Movement Science, 26, 867-891. https://doi.org/10.1016/j.humov.2007.07.002

Ripich, D. N., Vertes, D., Whitehouse, P., Fulton, S., \& Ekelman, B. (1991). Turn-taking and speech act patterns in the discourse of senile dementia of the Alzheimer's type patients. Brain and Language, 40(3), 330-343. https://doi.org/10.1016/0093-934X(91)90133-L

Sakamoto, M., Ando, H., \& Tsutou, A. (2013). Comparing the effects of different individualized music interventions for elderly individuals with severe dementia. International Psychogeriatrics, 25(5), 775-784. https://doi.org/10.1017/s1041610212002256

Salimpoor, V. N., Benovoy, M., Larcher, K., Dagher, A., \& Zatorre, R. J. (2011). Anatomically distinct dopamine release during anticipation and experience of peak emotion to music. Nature Neuroscience, 14(2), 257-262. https://doi.org/10.1038/nn.2726

Salimpoor, V. N., Van Den Bosch, I., Kovacevic, N., McIntosh, A. R., Dagher, A., \& Zatorre, R. J. (2013). Interactions between the nucleus accumbens and auditory cortices predict music reward value. Science, 340(6129), 216-219. https://doi.org/10.1126/science.1231059

Salimpoor, V. N., Zald, D. H., Zatorre, R. J., Dagher, A., \& McIntosh, A. R. (2015). Predictions and the brain: How musical sounds become rewarding. Trends in Cognitive Sciences, 19(2), 86-91.

https://doi.org/10.1016/j.tics.2014.12.001

Särkämö, T., Tervaniemi, M., Laitinen, S., Numminen, A., Kurki, M., Johnson, J. K., ... Rantanen, P. (2014). Cognitive, emotional, and social benefits of regular musical activities in early dementia: Randomized controlled study. The Gerontologist, 54(4), 634-650. https://doi.org/10.1093/geront/gnt100

Schiaratura, L. T. (2008). Non-verbal communication in Alzheimer's disease. La Communication Non Verbale Dans La Maladie d'Alzheimer., 6(3), 183-188. https://doi.org/10.1684/pnv.2008.0140

Schiaratura, L. T., Di Pastena, A., Askevis-Leherpeux, F., \& Clément, S. (2015). Expression verbale et gestualité dans la maladie d' Alzheimer : une étude en situation d' interaction sociale. Geriatrie et Psychologie Neuropsychiatrie Du Vieillissement, 13(1), 97-105. https://doi.org/10.1684/pnv.2014.0514

Schino, G., \& Troisi, A. (1992). Opiate receptor blockade in juvenile macaques: effect on affiliative interactions with their mothers and group companions. Brain Research, 576(1), 125-130. https://doi.org/10.1016/00068993(92)90617-I

Sherratt, K., Thornton, A., \& Hatton, C. (2004). Music interventions for people with dementia: A review of the literature. Aging and Mental Health, 8(1), 3-12. https://doi.org/10.1080/13607860310001613275

Shimokawa, A., Yatomi, N., Anamizu, S., Torii, S., Isono, H., Sugai, Y., \& Kohno, M. (2001). Influence of deteriorating ability of emotional comprehension on interpersonal behavior in Alzheimer-type dementia. Brain and Cognition, 47(3), 423-433. https://doi.org/10.1006/brcg.2001.1318

Sihvonen, A. J., Särkämö, T., Leo, V., Tervaniemi, M., Altenmüller, E., \& Soinila, S. (2017). Music-based 
interventions in neurological rehabilitation. The Lancet Neurology, 16(8), 648-660.

https://doi.org/10.1016/S1474-4422(17)30168-0

Sisco, F., Taurel, M., Lafont, V., Bertogliati, C., Baudu, C., Giordana, J. Y., ... Robert, P. (2000). Les troubles du comportement chez le sujet dément en institution: évaluation à partir de l'inventaire neuropsychiatrique pour les équipes soignantes (NPI/ES). L'Année Gérontologique, 14, 151-173.

Small, J. A., Geldart, K., Gutman, G., Ann, M., \& Scott, C. (1998). The discourse of self in dementia. Ageing and Society, 18.

Spielberger, C. D., Gorsuch, R., Lushene, R. E., Vagg, P. R., \& Jacobs, G. A. (1983). Manual for the State-Trait Anxiety Inventory. Palo Alto, CA: Consulting Psychologists Press. Retrieved from http://ubir.buffalo.edu/xmlui/handle/10477/1873

Suzumura, S., Osawa, A., Nagahama, T., Kondo, I., Sano, Y., \& Kandori, A. (2016). Assessment of finger motor skills in individuals with mild cognitive impairment and patients with Alzheimer's disease: Relationship between finger-tothumb tapping and cognitive function. Japanese Journal of Comprehensive Rehabilitation, 19-28.

Svansdottir, H. B., \& Snaedal, J. (2006). Music therapy in moderate and severe dementia of Alzheimer's type: A case-control study. International Psychogeriatrics, 18(4), 613-621. https://doi.org/10.1017/S1041610206003206

Tarr, B., Launay, J., \& Dunbar, R. I. M. (2014). Music and social bonding: "self-other" merging and neurohormonal mechanisms. Frontiers in Psychology, 5(1096). https://doi.org/10.3389/fpsyg.2014.01096

Toot, S., Swinson, T., Devine, M., Challis, D., \& Orrell, M. (2017). Causes of nursing home placement for older people with dementia : a systematic review and metaanalysis. International Psychogeriatrics, 29(2), 195-208. https://doi.org/10.1017/S1041610216001654

Tzortzis, C., Goldblum, M. C., Dang, M., Forette, F., \& Boller, F. (2000). Absence of amusia and preserved naming of musical instruments in an aphasic composer. Cortex, 36(2), 227-242. https://doi.org/10.1016/S0010-9452(08)70526-4

Ueda, T., Suzukamo, Y., Sato, M., \& Izumi, S. I. (2013). Effects of music therapy on behavioral and psychological symptoms of dementia: A systematic review and metaanalysis. Ageing Research Reviews, 12(2), 628-641. https://doi.org/10.1016/j.arr.2013.02.003

van der Steen, J. T., Van Soest-Poortvliet, M. C., Van Der Wouden, J. C., Bruinsma, M. S., Scholten, R. J., \& Vink, A. C. (2018). Music-based therapeutic interventions for people with dementia ( Review ). Cochrane Database of Systematic Reviews, 7. https://doi.org/10.1002/14651858.CD003477.pub3.www.c ochranelibrary.com

van Ulzen, N. R., Lamoth, C. J. C., Daffertshofer, A., Semin, G. R., \& Beek, P. J. (2008). Characteristics of instructed and uninstructed interpersonal coordination while walking side-by-side. Neuroscience Letters, 432(2), 88-93. https://doi.org/10.1016/j.neulet.2007.11.070

Warren, J. D., Warren, J. E., Fox, N. C., \& Warrington, E. K. (2003). Nothing to Say, Something to Sing: Primary Progressive Dynamic Aphasia. Neurocase, 9(2), 140-155. https://doi.org/10.1076/neur.9.2.140.15068

Wiltermuth, S. S., \& Heath, C. (2009). Synchrony and cooperation. Psychological Science, 20(1), 1-5. https://doi.org/10.1111/j.1467-9280.2008.02253.x

Yan, J. H., Rountree, S., Massman, P., Doody, R. S., \& Li, H. (2008). Alzheimer's disease and mild cognitive impairment deteriorate fine movement control. Journal of Psychiatric Research, 42(14), 1203-1212. https://doi.org/10.1016/j.jpsychires.2008.01.006

Zhang, H., Gross, J., De Dreu, C., \& Ma, Y. (2018). Oxytocin promotes synchronized out-group attack during intergroup conflict in humans. ELife, 8, e40698. https://doi.org/10.7554/eLife.40698 